\title{
Exposure to Anthropogenic Activities and Age Class Mediate Movement-Explicit Habitat Selection of A Mesocarnivore in A Human-Dominated Landscape
}

\section{Laurel Serieys ( $\sim$ Laurel@fwob.org)}

University of Cape Town https://orcid.org/0000-0002-0399-6646

Jacqueline M Bishop

University of Cape Town Department of Botany: University of Cape Town Department of Biological

Sciences

\section{Matthew S Rogan}

University of Cape Town Department of Biological Sciences

Justine A Smith

University of California Davis

Jusin P Suraci

University of California Santa Cruz

M Justin O'Riain

University of Cape Town

Chris C Wilmers

University of California Santa Cruz

\section{Research}

Keywords: urbanization, functional response, step selection functions, caracal, fire, mesocarnivore, age class

Posted Date: February 19th, 2021

DOI: https://doi.org/10.21203/rs.3.rs-213810/v1

License: (c) (i) This work is licensed under a Creative Commons Attribution 4.0 International License. Read Full License 


\section{Abstract}

Background: Wildlife populations are increasingly challenged by human activities that disrupt landscape connectivity and animal movement, and thus population dynamics and persistence. Yet modified habitats may provide resource subsidies for generalist species resulting in increased selection of disturbed areas. Understanding how species adjust their space use and activity in human-modified landscapes is increasingly critical to conserving wildlife populations globally.

Methods: To test three competing hypotheses explaining spatiotemporal responses to human activity, we GPS-collared 26 individual adults and subadults from three contiguous subpopulations in wildland and urban-dominated regions. We investigated coarse (3 hour)- and fine (20 minute)- scale movement-explicit habitat selection using step selection functions and tested for increased nocturnality of caracals (Caracal caraca) in a human-dominated landscape in South Africa.

Results: Caracals in a wildland-dominated landscape were on average $>8.0 \mathrm{~km}$ from the urban-natural boundary and strongly selected for proximity to the coastline. Caracals in the urban-dominated landscape were on average $<500 \mathrm{~m}$ from the urban-natural boundary, yet strongly avoided areas within the urban matrix itself while selecting for close proximity to the urban-natural boundary. Caracals avoided vegetative cover in the wildland-dominated region but selected for vegetative cover in the urbandominated region, likely to conceal themselves from detection by humans. Selection responses for vineyards, freshwater, the coast, and burned areas was dependent on age class, diel period, and whether individuals were in close proximity to urban areas. Caracals inhabiting the urban-dominated region did not shift their temporal activity patterns to avoid contact with humans, but they selected for closer proximity to urban areas at night, suggesting they seek spatial refugia during the day.

Conclusions: Behavioral plasticity whereby individuals seek out spatial, but not temporal refugia, appears to promote the coexistence of this generalist carnivore in a human-dominated landscape. Both age class and degree of exposure to anthropogenic activities influence habitat selection, while some individuals have learned to successfully exploit the riskiest areas at night. These data are essential to our understanding of what is viable wildlife habitat in this rapidly urbanizing landscape and provide opportunities to guide land acquisition and conservation guidelines by local management agencies.

\section{Background}

Human activities affect nearly every terrestrial system on earth [1]. Diverse consequences include habitat loss, changes in size, structure, and connectivity of remaining natural habitat [2], and shifted ecosystem processes, disturbance regimes (e.g. fire [3]), and resource availability [4]. Human infrastructure directly impedes animal movement [5], while human activity can elicit fear in individuals, causing them to shift movement patterns and habitat selection [6,7]. For those species that persist in human-impacted landscapes, they are also confronted with vehicles, poisons, and pathogens that can increase mortality [8] and reduce fitness $[9,10]$. The Anthropocene is thus characterized by rapid loss in global biodiversity 
and ecosystem services $[11,12]$. Yet some species are remarkably successful at adapting, persisting, and even thriving in human-modified landscapes [12]. Understanding the mechanisms that facilitate persistence in human-dominated landscapes is increasingly fundamental to modern biodiversity conservation [13].

An animal's immediate response to disturbances is typically behavioral (e.g. altered habitat selection, activity, or vigilance [14]), and thus behavioural plasticity is essential to population persistence in changing environments [15]. A critical determinant of landscape use by animals is the perception of risk, whereby individuals must balance the rewards (e.g., attaining food or shelter) with the potential costs (e.g., predation, $[7,10])$. Human activity typically elicits fear responses in wildlife equal to or exceeding those caused by non-human predators [16,17]. In some disturbed landscapes where humans are ecologically perceived as apex predators [17], consequent changes in animal behavior have important implications for wildlife communities and ecosystem processes [18].

Quantifying animal movement, space use, activity, and habitat selection across a range of human footprints informs the perceived risk-reward tradeoffs in anthropogenic landscapes $[16,19,20]$. Habitat selection and spatial avoidance of human activity depends on the specific behavior under consideration (e.g., forage, rest, reproduce, defend territories, disperse, $[6,20,21])$, while movement itself enables animals to [22] fulfill these needs [20,22]. Functional responses (adjustments in selection of a resource or landscape features as a function of changes in the availability of that resource or particular landscape features) can reveal whether animals perceive particular habitats as risky and provide insight into the cumulative effects of anthropogenic development on wildlife populations [23], and spatial distribution dynamics $[24,25]$. Coupling behaviors with spatial locations to understand behavioural responses to heterogenous landscape features is essential to define habitat suitability, which can be incorporated into land-use planning [26].

Studies examining wildlife habitat selection, occupancy, and activity in human-dominated landscapes have frequently found that wildlife species may mitigate anthropogenic disturbances by partitioning space, time, or microhabitats $[19,27,28]$. By segregating the landscape spatially, sometimes at fine-scales [18,29-31], species can avoid direct spatial overlap with humans. Yet spatial refugia are not always available, and thus animals may avoid diurnal human activity through increased nocturnality (reviewed in [27]). A growing body of literature is demonstrating that the presence of well-vegetated microhabitat can facilitate landscape use by wildlife even in areas with high human activity through mitigating the risk of detection $[19,28,32]$.

Defaunation in the Anthropocene is a non-random process. Large-bodied carnivores with substantial spatial requirements and low recruitment rates are often the first species to be extirpated in disturbed habitats [33,34]. This relative sensitivity to human disturbance is multifaceted, but loss of prey [35] and both direct and indirect human-induced mortality [8] likely play important roles in their extirpation. Mesocarnivores may also have large spatial requirements, low density populations [33], and suffer frequent mortality linked to human-activities [8,36], but they are notorious for their ability to persist, and 
even thrive, in human-dominated landscapes [37]. Often the success of mesocarnivores is simplistically attributed to a release from top-down processes (i.e., 'mesopredator release'), although evidence for this is in human-impacted systems is mixed [38,39]. Rather, in human-dominated systems with altered ecosystem dynamics, this success may also be mediated by habitat heterogeneity and resource abundance [40-42].

Here we investigate the behavioral response of a mesocarnivore to the interrelated effects of anthropogenic development and ecological variation in a fragmented, dynamic (e.g. fire-prone) landscape isolated by dense urbanization in the City of Cape Town, South Africa. The caracal (Caracal caracal) is a medium-sized, ecological generalist, and is widely considered a conflict species across southern Africa they are particularly reviled in small livestock farming areas where they thrive [36] despite being heavily persecuted for livestock losses (e.g. [43]). Recent studies confirm the persistence of caracals in large protected areas adjacent to urban areas [44,45], small reserves surrounded by urban development [46], and within heavily modified residential estates [47], which may act as an ecological trap where they are exposed to pathogens [48] and poisons [45]. These studies point to both risks and rewards to life on the urban edge for caracals.

\section{Methods}

\section{Study area}

We assessed habitat selection and activity of free-ranging caracals on the Cape Peninsula and within a small nature reserve (False Bay Nature Reserve, Fig.1a), both of which are isolated from other populations by dense residential and commercial development within the municipal limits of the City of Cape Town (Fig. 1a). The City of Cape Town has an average population density of 1,530 people $/ \mathrm{km}^{2}$ (Statistics South Africa Census 2011, statssa.gov.za/). Within the Cape Peninsula, we primarily sampled individuals in Table Mountain National Park (TMNP), which encompasses approximately $320 \mathrm{~km}^{2}$ of fragmented, natural habitat, which we split into two regions (Fig. 1).

The 'urban-dominated region' of the study area comprises five habitat patches that encompass $187 \mathrm{~km}^{2}$ (northern half, Fig. 1), 78.4\% of which is bordered by urban area. We sampled two additional individuals in an urban-dominated region within the small fragmented False Bay Nature Reserve (comprising $<3 \mathrm{~km}^{2}$ ) surrounded by an extremely densely populated region of Cape Town (Cape Flats human population densities: 9,000-17,000 people/km²). The 'wildland-dominated region' (southern half, Fig. 1) encompasses $133 \mathrm{~km}^{2}, 46.2 \%$ of which is bordered by urban area. This region consists largely of contiguous protected national park areas and small patches of vineyards (3.9\%). In both regions, land uses include low to high density urban development, light industrial and commercial areas, golf courses, vineyards, eucalyptus stands, and pine plantations (urban-dominated region only). The fynbos biome dominates the natural areas of both the urban- and wildland-dominated regions and is comprised of extremely diverse, low-growing, dense shrubland with a fire-dependent ecology [49]. Across the study 
period, $35.2 \%$ of the available wildlife habitat in the study area intensively burned. Extensive coastal sand dune fields are also a common natural feature throughout the study area.

\section{Capture and GPS-collaring}

We sampled 29 caracals spanning the period 2014-2016. Individuals were sampled throughout the urbandominated region, while in the wildland-dominated region, our permits constrained sampling to the southern-most location (Cape of Good Hope Nature Reserve, Fig. 1a) furthest (15.8 km) from urban development in our study area. Captured animals weighed a minimum of $6 \mathrm{~kg}$ so that the collar weighed no more than $3 \%$ of the animal's body weight. Individuals were chemically immobilized, and we recorded age class, sex, weight, and morphological measurements. Individuals were classified as subadults ( $<2$ years) or adults ( $>2$ years) based on body size, weight, tooth wear and eruption, and reproductive status [50]. Individuals were fit with Tellus $1 \mathrm{C}$ collars (Followit ${ }^{\mathrm{TM}}$, Lindesberg, Sweden) that collected GPS locations at three-hour intervals throughout the $24 \mathrm{hr}$ cycle. To assess fine-scale movement patterns and the use of potential movement corridors through urban areas, we increased the GPS-sample rate to 20minute intervals every $10^{\text {th }}$ day for $24-36$ consecutive hours (resulting in a target of 72-96 consecutive locations). Collar data were downloaded via that Followlt ${ }^{\text {TM }}$ GEO web interface or obtained directly from collars after units dropped-off. Collars were equipped with both a timed drop-off mechanism and a rot-off cotton spacer to ensure eventual drop-off.

\section{Landscape covariates}

Caracals primarily used undeveloped habitat patches with intact shrubland vegetation (hereafter 'natural areas'), and to a lesser extent, areas within the fully transformed urban matrix (consisting of commercial, industrial, residential, and altered open areas). Therefore, to capture the influence of the urban matrix on caracal habitat selection, we used distance measure (URBAN.DIST) that fell along a continuum of negative to positive values, where 0 indicated the line (in our GIS layer, Supplemental Table S1) demarcating the urban matrix-natural area boundary (hereafter 'urban-natural boundary'). Negative values represented the distance inside the urban matrix measured from the urban-natural boundary whereas positive values represented the distance into natural areas measured from the urban-natural boundary. We also tested whether the availability of COVER influenced URBAN.DIST selection (COVER $x$ URBAN.DIST).

To control for the relative influences of both natural and anthropogenic landscape features on caracal habitat selection (modelling approach described below), we tested the influence of a suite of natural features including topography (SLOPE, ELEVATION), distance from freshwater (WATER.DIST) and coastline (COAST.DIST), and whether individuals were located within sand dune fields (DUNES). We used three different measures of vegetation: i) Cover (COVER, binary), ii) normalized difference vegetation index (NDVI, continuous), and iii) habitat burn intensity (BURN, normalized burn ratio 2 [NBR2], continuous). Vegetative COVER was an indicator variable (high cover: intact fynbos, vineyard vines, pine plantations, etc., low cover: bare ground, beaches, manicured grass lawns, etc.). 
Because of frequent wildfires, we attempted to sample NDVI and NBR2 covariates within a two-week time point of each GPS-point (matching the frequency of Landsat Spectral 8 updates, usgs.gov) although in some cases, daily cloud cover precluded our ability to do so. Thus, for all locations, we extracted the nearest time point for which information was available (Supplemental Methods). The median time difference between location date and vegetation index date was seven days for 3-hour fix intervals (mean $=23$ days, $S D=27)$ and six days for 20 -min fix intervals (mean $=19$ days $S D=26$ ).

Other anthropogenic landscape features included pine plantations (PINE), eucalyptus stands (EUCALYPTUS), vineyards (VINEYARDS), and distance from arterial roads (ROAD.DIST, high traffic primary and secondary roads [51]). In the wildland-dominated region, ROAD.DIST and URBAN.DIST were highly colinear (VIF > 20). We thus used only URBAN.DIST in model-fitting.

Each categorical variable was converted to indicator covariates (VINEYARD, EUCALYPTUS, PINE, DUNES, COVER). All covariates were standardized (mean $=0$, standard deviation $=2$, [52] with the exception of URBAN.DIST in the urban-dominated region, which was standardized by two standard deviations because the URBAN.DIST distribution for available locations (see modelling approach below) was disproportionately skewed towards negative values. Importantly, this method of standardizing URBAN.DIST did not change the selection coefficients that resulted from models; rather this standardization approach to aid in our ability to create representative plots of the relative probability of selection for URBAN.DIST (e.g., Fig 2). We calculated variance inflation factors (VIF) to ensure that no two covariates were strongly colinear (VIF $\leq 3.0$ in all cases, [53]). Further details for each covariate are reported in the Supplemental Methods and Supplemental Table S1.

\section{Movement-explicit step selection functions}

We analyzed movement-explicit habitat selection using step-selection functions (SSFs [54]). To ensure we used only movement relocations, we filtered consecutive GPS-locations to have $\geq 50$-meter step lengths (for both 3-hour and 20-min fix intervals) because, for both fix intervals, a 50-meter step length was the validated criteria for classifying GPS-clusters that formed when caracals in our study area were explicitly engaged in feeding or resting [44].

Caracals in the urban and wildland-dominated regions were subset for analyses because: i) there were stark contrasts in the degree of fragmentation by urbanization in the two-regions and sampling approach (described above), and ii) the distribution of the distance of available points from the urban matrixnatural boundary also varied substantially (Supplemental Table S2). Caracals were thus split into three subgroups: i) five adults in the wildland-dominated region, ii) seven subadult males in the urbandominated region, and iii) 14 urban adults in the urban-dominated region. Two subadult females in the urban-dominated region were included in the adult group because, unlike subadult males, they moved and used the landscape similar to adult females in their respective areas. Specifically, their median step length and their average distance from urban-natural boundary were similar, and for the one subadult female for which we were able to assess home range, her home range extensively overlapped the adult female in the same area (Serieys, unpubl.data). 
We performed SSFs on both 3-hour and 20-min interval data separately using a 1:20 match-case control empirical design. Strata were created where each individual's end 'used' location ( $t$ ) was paired with 20 'available' locations $[55,56]$. 'Available' locations were created using random vectors originating from the location immediately preceding 'used' location $t$ (i.e., location $t-1$ ). Random vectors were drawn based on the empirical distribution of turn angles and step lengths between consecutive locations derived from data on all individuals that were the same sex and age group as the focal individual but excluding the focal individual to avoid circularity [56]. For both fix intervals, three resource-independent movement parameters (STEP, LOG.STEP, and DIR.PERSIST) were calculated for all steps within each stratum to control for inherent biases in animal movement that influence habitat use $[6,55,57,58]$. For the fine scale 20-min interval data subset, we additionally calculated terms to control for potential tendency for movement along the same topographic gradient (SLOPE.PERSIST). See Supplemental Methods for more details about these behavioral parameters.

To correct for autocorrelation inherent in movement datasets, we calculated robust standard errors for selection coefficients using generalized estimating equations (GEE [59-61] by specifying intra-group ('cluster') correlation [59,61]. To specify clusters, we used a destructive sampling approach described by [61] which required that we first estimate the time lag past which temporal autocorrelation between successive caracal locations is no longer significant $(a=0.05)$. We fit an intercept-only mixed-effects model [57] and plotted the autocorrelation function of the model (Supplemental Fig. S1). Autocorrelation decayed after a lag of 54 hours.

We collected data during 31 collaring events from 25 unique individuals. Prima et al. [61] recommend a minimum of 20 clusters per analysis group. Thus, we destructively sampled our data (by removing 54 hours of data between successive clusters) resulting in 1-6 clusters per collaring event (31 adult and 27 subadult male clusters in the urban-dominated region, and 24 adult clusters in the wildland-dominated, range: $13-92$ days/cluster). Because 20 -min data collection occurred every $9^{\text {th }}-10^{\text {th }}$ day, we assigned clusters according to the individual ID and consecutive period of collection, resulting in a total of 277 clusters. To assess whether habitat selection varied with differing degrees of exposure to human activities, we divided our data into diel period based on local sunset and sunrise times. We defined night as the period when the sun is at least $9^{\circ}$ below the horizon.

We estimated selection (ß) coefficients using the coxph function in the survival package [62] for $R$ statistics software [63]. A primary objective was to evaluate the relationship between proximity to the urban matrix and habitat selection. Thus, we built our modelling framework around the URBAN.DIST covariate. We had two a priori expectations regarding the relationship between URBAN.DIST and caracal habitat selection: i) the relationship may be non-linear, and ii) the relationship may differ between caracals in the wildland-dominated $v s$. urban-dominated regions. Thus, for all subgroups, we first evaluated whether the relationship was best-captured using a simple linear, quadratic-transformed, logtransformed URBAN.DIST, or a segmented linear spline regression approach. 
The segmented linear spline regression approach split the distance from the urban-natural boundary into two (or three) covariates with different slopes on either side of a breakpoint [64]. We selected the optimal breakpoint (hereafter 'knot') using a grid search approach by comparing quasi-likelihood under independence criterion (QIC) scores of candidate spline models (Supplemental Fig. S2) and selecting that with the lowest QIC. QIC is a criterion suggested by [59] as best for comparing model performance in GEEbased analyses.

We tested candidate knot values at one meter intervals ranging between the minimum and maximum standardized distances from the urban-natural boundary. At the scale of one meter intervals, multiple well-supported knots were identified $(\Delta \mathrm{QIC}<2)$ but the difference in distances among the well-supported knots was trivial $(<10 \mathrm{~m})$. Thus, we averaged well-supported candidate knot values to obtain a single value. To validate the use of segmented regressions, we performed the segmented regression approach on each caracal subgroup and compared the segmented model QIC with models with a simple linear, logtransformed, or quadratic-transformed distance from the urban-natural boundary. The segmented approach performed best for caracal subgroups in the urban-dominated region, whereas the quadratic transformed distance performed best for caracals in the wildland-dominated region.

Next, for each caracal subgroup in the urban-dominated region, we split their data according to diel period, and performed the same grid search approach to determine whether the optimal knot shifted for each diel period. Subadults and adults thus had three knot values each (day, night, composite [day and night] dataset), ranging between 44-153 $\mathrm{m}$ from the urban-natural boundary. These values indicate that there exists a narrow (natural area) buffer zone around the urban matrix that caracals perceive as equal to the urban matrix itself (Fig. 2a-c). We hereafter refer to the urban matrix and the surrounding narrow, natural buffer zone as the 'urban interface.'

For caracals in the urban-dominated region, we next considered that the relative probability of selecting certain landscape features was dependent on where individuals encountered this feature (urban interface vs. natural area). We considered this possibility for candidate covariates PINE, BURN.INDEX, COVER, ELEVATION, WATER.DIST, and COAST.DIST (hereafter 'split' covariates). We predicted the potential for split PINE, BURN.INDEX, and COVER because these features are indicative of available vegetative concealment that may be more strongly selected (i.e., COVER) or avoided (i.e., PINE, BURN.INDEX) within the urban interface where concealment would mitigate detection risk. Within the urban interface, we predicted that the relative importance of ELEVATION would diminish substantially. WATER.DIST within the urban interface may be linked with increased opportunity to find urban-associated prey (e.g., Egyptian geese, Alopochen aegyptiaca [44]). Finally, we considered a split potential for COAST.DIST because we predicted that caracals would avoid coastline closely bordered by residential or commercial development. We did not consider a split potential for NDVI, DUNES, VINEYARDS, EUCALYPTUS, or ROAD.DIST (hereafter 'simple' covariates), because with rare exception, roads and eucalyptus were primarily located within, or in close proximity to, the urban interface, while vineyards were always directly adjacent to the urban interface. We could not think of a biological reason why selection for DUNES or NDVI would differ with proximity to the urban-natural boundary. 
To adapt our modelling approach to incorporate split covariates in urban models, we created an indicator variable $I$, where $I=1$ when an individual was within natural areas, and $I=0$ when individuals were located within the urban interface. This allowed us to model parameters $a_{n}$ representing the selection estimate when individuals were within the urban interface, and $a_{n}+\beta_{n}$ representing the selection estimate when individuals were within natural areas. For caracals in the urban-dominated region, we thus adapted our model as follows:

$\mathrm{w}(\mathrm{x})=\exp \left(\beta_{1} x_{1}+\left(\mathrm{a}_{2}+\beta_{2}\right) x_{2} \ldots \beta_{n} x_{n}+\left(\mathrm{a}_{n}+\beta_{n}\right) x_{n}\right)$

In contrast, for caracals in the wildland-dominated region, we calculated the relative probability of selection $w$ for landscape covariate $x$ using coefficients $ß$ via the standard exponential model [65]:

$\mathrm{w}(\mathrm{x})=\exp \left(\beta_{1} x_{1}+\ldots \beta_{n} x_{n}\right)$

Finally, for each of the three caracal subgroups, diel period-, and fix interval-specific data subset, we modeled the relative probability of a caracal selecting a particular location as a function of NDVI, BURN, ELEVATION (or SLOPE, wildland-dominated fine-scale data subset), COVER, EUCALYPTUS, VINEYARD, PINE, COAST.DIST, WATER.DIST, URBAN.DIST, ROAD.DIST and interaction URBAN.DIST x COVER). For caracals in the urban-dominated region, we tested an additional interaction URBAN.DIST $x$ ELEVATION to assess whether caracals select for proximity to the urban-natural boundary simply because the urbannatural boundary tends to be at low elevations in this region of the study area. For each subset, we fit models consisting of every combination of these terms and compared the QIC of all resulting models. In cases where $>1$ candidate best-fit model was identified with a $\Delta \mathrm{QIC}<2$, we selected the most parsimonious model (the model with the fewest coefficients). In cases where there were two models with the same number of terms and $\Delta \mathrm{QIC}<2$, we selected that with the lowest QIC to report in figures and results, and report both competing best-fit models in the Supplemental Tables. For all top models, we report the selection coefficient $B$, and $95 \%$ confidence intervals calculated using the robust standard errors (Supplemental Tables S3-S13).

\section{Cross validation}

To evaluate the robustness of all top (best-fit) models we used 5-fold cross validation following $[32,66]$. We built case-control SSFs using covariates retained in the top model fit to $80 \%$ of randomly selected strata. We used this model to predict $w(\mathbf{x})$ scores for used and available locations from the $20 \%$ of withheld strata. For each stratum comprising used $(n=1)$ and available $(n=20)$ movement locations, we calculated the $w(\mathbf{x})$ score which was then used to assign each location a rank of 1 to 21 (lowest to highest). We next used spearman rank correlations to compare the frequency with which the withheld used locations received each of the 21 possible rankings. We iterated this process 100 times for each top model. We report the mean and standard deviation values of Spearman correlation coefficients $\left(r_{s}\right)$ across all iterations (Table 1). Models with strong predictive power exhibit mean $r_{s}$ values close to 1 . We 
also report mean $r_{s}$ values expected under random habitat selection (i.e., if models have no predictive power [66]).

\section{Activity in high risk areas}

We assessed relative activity patterns to test whether caracals in the urban-dominated region changed activity patterns mitigate risk of detection in areas with high (lethal and nonlethal) human activity [27]. We additionally assessed whether subadults in the urban-dominated region alter activity patterns to avoid interactions with adults. We thus defined risk as a function of whether: i) individuals utilized the urbandominated region (as opposed to the low-risk wildland-dominated region), and ii) individuals were of the subadult male demographic For risk scenario (i), we compared the activity data of four adults from the wildland-dominated region, and 12 adults from the urban-dominated region (for which we had 20-min data). For risk scenario (ii), we compared the activity data of 12 adults to the data of six subadult males in the urban-dominated region. We assessed effect size using log risk ratios ("RR",[27]) calculated from 20-min fix interval data that we subsampled to one-hour intervals to reduce autocorrelation (as in $[67,68]$ ). $\mathrm{RR}$ is a ratio of the mean nocturnality at sites of high human disturbance to the mean nocturnality at sites of low human disturbance. We defined each caracal observation as "active" if individuals moved $\geq 50$ meters in the 20-minutes preceding each one-hour observation (otherwise, the time point was classified as "inactive"). This selected movement threshold is consistent with the threshold described above to isolate movement locations from the larger GPS dataset, and follows the approach previously described for classifying active periods based on GPS-movement data [67].

Our dataset was skewed towards more daytime than nighttime locations because 20-min data were collected for an interval of 36-hours beginning at 02:00. We thus used bootstrap resampling to control for individual effects and maintain even sampling among individuals. We sampled without replacement 24 daytime observations and 24 nighttime observations for each caracal for 1000 replications. For each replicate, we calculated the log proportion of active observations that occurred during the night for populations in both the urban-dominated and wildland-dominated regions. We report a weighted mean log RR with weights assigned according to the inverse variance of each replicate, the proportion of replicates for which nocturnality was greater in the population in the urban-dominated region, and the $95 \%$ bootstrap confidence interval based on the $25^{\text {th }}$ and $95^{\text {th }}$ greatest RRs. To interpret our results of these analyses, we back-transformed mean effect sizes and converted to unlogged risk ratios to assess percent shift towards nocturnality in areas of high risk. We assessed significance using confidence intervals- those that overlapped zero were not significant.

\section{Results}

\section{Sampling}

We captured 29 individuals over a period of roughly 3,500 cage trap nights and GPS-collared 25 unique individuals presented in this study. Of the collared individuals, six individuals ( 2 adult males, 4 adult 
females) were captured in the wildland-dominated region, while 19 unique individuals ( 6 adult males, 6 females, 7 subadults) were sampled across the urban-dominated region. However, one individual in the wildland-dominated region presented a unique case. In brief, after being initially detected preying on endangered African penguins (Spheniscus demersus), the City of Cape Town and South Africa National Parks (SANParks) decided to capture, GPS-collar, and relocate her (on the day of capture) $21 \mathrm{~km}$ north to the urban-dominated region. We excluded the first 23 days (during which time her movements stabilized after she established a home range, Serieys unpubl.data) of her data but included subsequent locations in SSFs and classified her as belonging to the urban-dominated region. As a result, we obtained data for five individuals in the wildland-dominated region and 20 individuals in the urban-dominated region.

Individuals were collared for an average of 123.0 days $(S D=49.6$, median $=132.0)$. Mean collar fix success was $92 \%$ (median $=94 \%$ ). In total, we collected data over a period of 3,812 tracking days. We collected a total of 26,292 3-hour GPS locations (Figure 1b, 17,424 filtered locations), and 26,639 20minute locations (8,962 filtered locations).

\section{Relationships with the urban-natural boundary and functional responses}

Caracals in the urban-dominated region exhibited functional responses with respect to the relative probability of selecting distance from the urban matrix-natural area boundary (Fig. 2-3, Supplemental Tables 3-11), segmented models were optimal for both adults and subadults. The (non-segmented) quadratic-transformed distance was the top model for caracals in the wildland-dominated region (Figure 4, Supplemental Tables 12-14). In the urban-dominated region, adults were on average $469.3 \mathrm{~m}$ (median = 353.5, SD $=463.2$ ) from the urban-natural boundary, whereas subadult males were on average only 45.1 $\mathrm{m}$ (median $=83.5, \mathrm{SD}=563.1)$ from the urban-natural boundary. Caracals in the wildland-dominated region were on average $8,014.7 \mathrm{~m}$ (median $=8,044.0, \mathrm{SD}=5,499.8$ ) from the urban-natural boundary. In the urban-dominated region, (controlling for sample size) there were 4.7 times as many subadult locations within the urban matrix itself compared with adults (subadults $=30.7 \%$, adults $=6.5 \%$ of locations). Overall, the overwhelming majority of caracal GPS locations, irrespective of demographic or sampling region, were situated in natural areas.

The sparsity of adult (especially) and subadult caracal locations within the urban matrix itself suggests the matrix is suboptimal habitat, whereas natural areas were strongly preferred. However, the segmented models (specific to caracals in the urban-dominated region) revealed that not all natural area is equal. Specifically, a narrow buffer zone of natural area surrounding the urban matrix was avoided equally to the urban matrix itself (Fig. 2a-c). The width of this buffer zone (determined via the knot value) shifted marginally according to diel period and dataset used (Table 1). Although subadult locations were closer to the urban-natural boundary, counterintuitively, subadult knot values were on average, 2.1 times further from the urban-natural boundary than adult knot values. The average buffer zone width (i.e., knot value) was $116.7 \mathrm{~m}$ for subadult $\mathrm{s}$, and $68.2 \mathrm{~m}$ for adults (Table 1). While we calculated knot values that represented the functional shift between urban and natural areas, we consider these to be rough estimations given that the urban matrix itself is extremely heterogenous (e.g. commercial areas, low to 
extremely high density residential areas). What drove the differences between urban adult and subadult knot values is unclear, except that on the scale of 3,000 meter of available natural area surrounding the matrix, the differences between the subadult and adult knot values appears trivial (e.g., Fig. 2a).

\section{Coarse-scale habitat selection varies across age, region, and diel period}

Multiple natural and anthropogenic features heavily influenced caracal habitat selection across the three subgroups, although unique trends emerged across subgroups (Fig. 2-7, Supplemental Tables S3-S14). We expect that the habitat selection of caracals in the wildland-dominated region (Fig. 4, Supplemental Tables S12-14) represents baseline habitat selection trends (with little human influence). Further, in cases where the habitat selection of adults in the urban-dominated region deviates from that of adults in the wildland-dominated region, we posit these differences represent behavioral adaptations of caracals in the urban-dominated region to frequent exposure to anthropogenic activities. Selection for sand dunes was universal across all best-fit models, while selection for greenness (NDVI) was near universal (with the exception of subadults at night). Overall, observed cross-validation scores were high, particularly for caracals in the urban-dominated region (Table 1). Observed $r_{s}$ scores for top models for caracals in the wildland-dominated region were lower, possibly as an artifact of smaller sample size, but still markedly outperformed $r_{s}$ values expected under random habitat selection.

In the wildland-dominated region, caracals generally avoided proximity to the urban-natural boundary, although this avoidance relaxed when cover (in close proximity to the urban matrix) was available at night. During the day, an interaction between available cover and distance from the urban-natural boundary was not in the best-fit model, suggesting that irrespective of available cover, these caracals avoided close proximity to the urban matrix when human activity was highest. Proximity to the coast was the strongest driver of caracal movement decisions in the wildland-dominated region (Fig. 4-5, Supplemental Tables S12-S14), although topographical covariate elevation was not in the composite or night top models, indicating that caracals selected for coastlines whether they were steep and rocky, or low sandy beaches. Indeed, caracals marginally selected for higher elevations during the day $(p=0.089)$, although selection for the coastline was strongest during the day. While these caracals selected for greenness (NDVI), they avoided vegetative cover, particularly at night, preferring instead open areas with high visibility. Unlike caracals in the urban-dominated region, they avoided proximity to freshwater. We were unable to assess the influence of vineyards and eucalyptus stands in this region because neither used nor available locations fell within these land use types.

Caracals in the urban-dominated region exhibited remarkably different trends in habitat selection, with some trends that also differed among age classes (Fig. 2-3,5-6, Supplemental Tables S3-S11). For adults in the urban-dominated region, they strongly avoided the 'urban interface' (the urban matrix surrounded by a narrow buffer of natural area of width determined by the knot values, Figure 2a-b). However, there were multiple lines of evidence that adults explicitly selected for close proximity to the urban interface even after controlling for elevation: i) at night, adults selected for close proximity to the urban interface, ii) when vegetative cover was available and they were situated in natural areas, adults caracals selected for 
close proximity to the urban interface (evident in the composite dataset, Fig. 3, Supplemental Table S3), and iii) a marginally $(p=0.054)$ significant interaction between URBAN.DIST and ELEVATION demonstrated that caracals avoided high elevations less if high elevations brought them into close proximity to the urban-natural boundary. Further, selection for proximity to freshwater was 2-3 times stronger when individuals were situated within the urban interface as opposed to when situated in natural areas. Contrary to our expectations, but in further support of selection for areas in close proximity to the urban-natural boundary, adults strongly selected for proximity to the coast when situated in the urban interface, whereas when situated in natural areas, the relationship with proximity to the coast was neutral. When situated in natural areas, selection for low elevations strongly influenced adult movement, whereas when situated in the urban interface, elevation had no effect. Yet at night, selection for low elevation areas was stronger when this selection brought them into closer proximity to the urban interface. Unlike adults in the wildland-dominated region, adults in the urban-dominated region selected for cover irrespective of whether they were within the urban interface or in natural areas (but see 20-min data models below). When situated within the urban interface, adults avoided burned areas, while when situated in natural areas, the relationship with burned areas was neutral (but see 20-min data models below, Fig. 6). Adult caracals in the urban-dominated region avoided vineyards and roads. Avoidance of roads was strongest during the day when vehicle traffic was greatest.

Habitat selection differed among urban adults and subadults, and of note, we detected evidence of subadult males avoiding adults (Fig. 2-3,5). Subadult male avoidance of the urban interface itself was 3.6 times lower than that of adults. Similar to adults, we observed explicit evidence of subadult selection for close proximity to the urban interface even after controlling for elevation: i) subadults selected for close proximity to the urban interface (evident in the composite dataset), ii) at night, when cover was available and individuals were situated in natural areas, selection for proximity to the urban interface shifted from neutral to positive selection (Fig. 3, 6a), and iii) selection of low elevation areas was stronger when that selection brought subadults in closer proximity to the urban interface (evident in the composite and night datasets). Further, like adults in the urban-dominated region, subadults strongly selected for proximity to freshwater when situated within the urban interface, while selection for proximity to freshwater was relaxed or neutral when subadults were situated within natural areas. Yet in contrast with adults in both regions, subadults strongly avoided the coast (Fig. 5), possibly to avoid interactions with adults. At night, when subadults were more likely to use the urban interface, they selected for low elevations (irrespective of whether situated within the urban interface or natural areas), whereas during the day, selection for low elevations was limited to when individuals were situated in natural areas. Yet when the use of high elevation areas brought subadults into closer proximity to the urban interface, they used higher elevations. Like adults in the urban-dominated region, subadult caracals selected for cover. Similar to adults in the urban-dominated region, subadults avoided burned areas, particularly when they were situated within the urban interface (e.g. Fig. 7). Unlike adults, subadults selected for vineyards, particularly at night when human activity was lowest. Finally, unlike adults, road avoidance was not detected. 
We also assessed fine-scale movement-specific habitat selection at 20-min because at this scale, the relative importance of natural landscape features in habitat selection has been shown to increase [6] and could provide important information to retaining viable corridors through fragmented habitat. Median step length across all individuals during 20-min intervals (filtered to isolate movement data) was 136.8 meters, indicating that habitat use decision is often on the scale of $<150 \mathrm{~m}$. Overall, as observed previously, the avoidance of anthropogenic features tended to relax, while selection for natural features tended to increase (Fig. 6b, 7), with the exception for dunes and elevation in the urban-dominated region (but not in the wildland-dominated region). However, a few important new trends emerged. Here, we present notable differences (Supplemental Tables S3-S14).

For adults in the wildland-dominated regions, the most notable differences we observed included selection for burned areas (Figure 7), lower slopes, and avoidance of eucalyptus. In the urban-dominated region, the most important difference detected was that, at night, adults selected for burned areas when they were situated in natural areas and avoided burned areas when they were situated within the urban interface (Figure 7). Interestingly, another dichotomous relationship emerged, cover was strongly selected when adults were situated within the urban interface at night, whereas when situated in natural areas, adults avoided vegetative cover (Supplemental Table S5). During the day, for both adults and subadults in the urban-dominated region, the relationship with elevation was neutral. Additionally, during the day for adults, the interaction between URBAN.DIST and COVER was particularly pronounced (Figure 6b). For subadults, primary differences included that avoidance of the coast was included in the best-fit model, and interestingly, at night, subadults selected against NDVI.

\section{Activity}

We filtered a total of 26,27820 -min locations to 8,582 hourly locations collected from 19 individuals. We found no significant differences in nocturnality among subgroups (Supplemental Fig. S3). The variancevariance weighted mean log risk ratio among the 1,000 bootstrap replications was -0.005 (equivalent to $0.5 \%$ greater nocturnality among wildland-dominate caracals), with $48.6 \%$ of replicates indicating greater nocturnality among adult caracals in the urban-dominated region (bootstrap confidence interval: -0.20 0.20). Overall, caracals were most active during crepuscular hours.

\section{Discussion}

Human activities increasingly isolate and disrupt wildlife populations through a range of disturbances. In extremely disturbed habitat (e.g., urban and agricultural areas), highly mobile species must navigate a broad spectrum of habitat suitability [69] often with increased risks. Yet this habitat modification may also result in an increase in resource abundance for generalist species, and in turn result in increased habitat suitability. We tested three hypotheses regarding whether caracals: i) completely (spatially and temporally) avoid human activities, ii) temporally avoid human activities, or iii) seek spatial refugia to shelter from human activities in the rapidly urbanizing landscape of the City of Cape Town. We 
additionally investigated potential differences in human-avoidance strategies among adults and subadult males in the urban-dominated region. We observed stark differences in habitat selection among caracals differing in (i) age class and (ii) living across urban- and wildland-dominated landscapes. Interestingly, we did not observe evidence of blanket avoidance of urban areas or shifted temporal activity patterns in areas with high human activities and thus reject our complete- and temporal-avoidance hypotheses. Rather, we found most support for the spatial refugia hypothesis, particularly when considering the role of well-vegetated microhabitats as refuges within the urban boundary. Further, the tolerance of anthropogenic disturbances differed depending on subgroup exposure to them.

\section{Differing selection for the urban edge among caracal subgroups}

Anthropogenic disturbances can shift species' space use to habitats perceived to have the most optimal suitability $[6,19,70]$. Here we focused on movement-explicit habitat selection because movement ties various life history behaviors together $[6,20,71]$. Disturbances in our system were not only manifest in habitat transformation but also recreational activities, fires, road traffic, and poaching (Serieys, unpubl.data). Caracals in the wildland-dominated region, with access to larger tracts of natural vegetation, used areas an average of 16 -fold further from urban areas than caracals living in smaller patches fragmented by urbanization. Despite this, caracals in the urban-dominated section of the study area, on average, selected for areas in close proximity $(50-500 \mathrm{~m})$ to the urban edge. Specifically, in the urban-dominated region, $75 \%$ of subadult male locations were within 270 $\mathrm{m}$ of the urban edge and $75 \%$ of adult locations were within $\sim 690 \mathrm{~m}$ of the urban edge. In stark contrast, in the wildland-dominated region, only $9 \%$ of adult locations were within $\sim 690 \mathrm{~m}$ from the urban edge. A similar trend of stronger avoidance of anthropogenic landscapes by individuals less exposed to anthropogenic activities was observed for pumas (Puma concolor) living in rural and wilderness areas [72]. In addition to documenting selection for close proximity to the urban-natural boundary itself, we observed that caracals also more strongly (or only) select for other landscape features (freshwater and the coast) when those features themselves are within the urban interface. Together, these observations strongly suggest that valuable resources lie within close proximity to the urban-natural boundary, particularly in the urban-dominated region, thus driving caracals in the urban-dominated region to selectively remain at the urban edge, where anthropogenic risks are higher.

\section{Movement explicit habitat-selection}

Several trends in habitat selection were common across all subgroups. Among the most consistent trends across subgroups was positive selection for greenness (measured by NDVI). While caracals generally selected for green spaces, the response to dense vegetation structure (measured as COVER), and its interaction with other predictor effects, was context-dependent. Adults in the wildland-dominated region generally avoided dense cover, particularly at night. In contrast, adults and subadults in the urbandominated region generally selected for cover, particularly when within the urban interface, whereas they sometimes avoided cover when in natural areas further from the urban-natural boundary. The adult response to COVER in the wildland-dominated region may represent baseline behavior for the species, 
and contribute to their success in extremely arid landscapes [73]. Complex vegetation offers the best cover for stalking prey $[74,75]$, but in the context of the disturbed landscape, selection for cover may rather reflect selection for concealment from humans [6,32].

Fires are an important driver of habitat disturbance in our study system and play a key role in shaping ecosystem structure and function, resource availability [76] and faunal populations $[77,78]$. The general expectation is that carnivores will avoid burned areas due to decreased prey availability and increased detection probability by humans $([79,80]$ but see [81]), despite the fact that fires can increase the nutritive value of post-fire successional vegetation [82], and increase species abundance of potential prey [82-84]. We found that caracals in the urban-dominated region exhibited a dichotomous selection-avoidance of burned areas with adults and subadults strongly avoiding burned areas when inside the urban interface but selecting for them in natural areas (a pattern particularly evident in the 20-min dataset, Fig. 7). Fynbos vegetation foliage that dominates our study area has little nutritive value for mammals [85], yet the seeds released post-fire can be extremely rich in energy and nutrients, and thus a valuable resource for small mammals [86]. Small mammals in fynbos ecosystems typically only leave burned areas several weeks after a fire [87]. With reduced cover as a result of fire, they may be more easily detected and preyed upon. Not only was this selection for burned areas evident in our habitat selection models, but we also observed in real-time several individuals to move into burned areas within a few days of the fire extinguishing. We conclude that caracals are attracted to recently burned areas outside the urban interface because of greater prey availability but avoid burned areas within the urban interface because they are too exposed to humans, which may be an example of sacrificing optimal foraging to avoid risky areas.

\section{Subadults pushed to the edge}

Young carnivores (particularly males) in populations disperse from their natal range [88]. Habitat selection for this age cohort is essential to understanding landscape features that promote connectivity $[89,90]$. In our peninsular system isolated by a dense urban matrix, successful dispersal out of the system appears near-impossible, and those young males that we observed attempt to leave the Peninsula and venture into the urban matrix were frequently hit by cars or turned back (Serieys, unpubl.data).

Nevertheless, while connectivity appears largely obstructed, our models yielded interesting differences in habitat selection amongst subadults and adults. These habitat selection differences are likely indicative of strategies that subadults use to avoid competition with adults.

Adults avoided the urban interface much more strongly than subadults suggesting that subadults are likely being pushed into marginal or risky habitat. Similar effects have been documented in numerous other carnivore species that inhabit human-dominated landscapes [90,91], including medium-sized felids such as bobcats (Lynx rufus) [92] and Iberian lynx (Lynx pardinus) [93]. Yet although 31\% of subadult male locations were within the urban matrix, the relative probability of selection for the urban matrix remained low. Subadults also selected for vineyards (which were not considered part of the urban matrix), while adults in the urban-dominated region avoided this land use. While the objective of this paper was 
not to describe in detail the differences in habitat selection between males and females, this trend may have been stronger if adult male habitat selection had been isolated during analyses, and this is a potential future line of enquiry.

Beyond utilizing human-modified areas to a greater degree (urban matrix and vineyards), subadults avoided the coastline, which may be further evidence of avoiding conflict with adults. In the Peninsular section of our study area, most of the available land is bordered by coastline which offers caracals access to abundant seabird prey [44]. Adults from both subpopulations selected for the coast, particularly at night (Fig. 5), where (wildland adults especially) regularly hunt coastal seabirds [44]. We did not capture subadults in the wildland-dominated region and thus are unsure whether this trend holds in the wildland-dominated region. However, the lack of subadult sampling may reflect subadult avoidance of the coast in the wildland-dominated region. While our time allotted to trap in the wildland-dominated region was substantially constrained by our permits, we were also constrained by only having access to areas within several hundred meters of the coastline. Thus, if subadults in the wildland-dominated region also avoid coastline because of dominant adult use of these areas, we were unlikely to sample the subadult demographic of the wildland population. Interestingly, we detected one opportunistic wildlanddominated region subadult at a feeding cluster after it was killed and consumed by an adult male in the area [44]. The threat imposed by competing with adults is substantial for younger individuals.

\section{Spatial refugia, not temporal refugia}

The mechanisms by which wildlife persist amongst human development are debated, but dominant hypotheses pivot on how individuals balance risk and energy gain [94]. Carnivore success in anthropogenic landscapes is considered to hinge on flexible behavior that accommodates human disturbance through functional responses, shifted activity patterns, and altered habitat selection $[6,72,95,96]$. Yet, carnivore habitat selection is largely driven by prey abundance [93] and perceived vulnerability to mortality risk [97]. In human-dominated landscapes, carnivores perceive humans as apex predators [17,98], and will adjust their behavior to avoid risk of conflict with people $[7,27,94,99]$. While we expected caracals in the urban-dominated region to avoid human encounters via shifted activity (relative to caracals in the wildland-dominated region), we found neither shifts in activity patterns nor increased nocturnality. Rather we detected bimodal activity patterns across all subgroups. Similar activity patterns have been documented in urban bobcats (Lynx rufus). and were attributed to natural life history behavior which includes rest during the day, travel to foraging areas at dusk, forage and rest during the night, and travel to resting areas at dawn [100]. Yet we have also observed caracals in the urban-dominated region to not only selectively forage at the urban edge, but also to initiate the majority of their kills $(61 \%)$ during the day (Leighton et al. in review), likely because some of their favored prey are diurnal (e.g. vlei rats, Otomys irroratus, Helmeted guineafowl, Numida meleagris, [44]). Thus, the combination of ample vegetative cover provided by natural fynbos near the urban edge, and the availability of prey at the urban edge, may rather drive our observed activity patterns. 
Rather than adopting a strategy of temporal refugia from human activity, caracals in the urbandominated region may adopt subtle spatial avoidance patterns that vary as a function of surrounding land-cover availability and proximity to perceived apex predators. During the day, adults in the urbandominated region avoided areas close to the urban interface that lacked thick cover (Fig. 6b, Supplemental Table S4). Adults in the urban-dominated region also avoided roads during the day when vehicle traffic is heaviest, but we did not detect this avoidance at night. When situated in areas of high human disturbance, animals may choose more protected areas or microhabitats [101], or if individuals are located near refuge habitat, they may tolerate closer approaches by potential predators [7]. Alternatively, the near constant exposure to human activities for caracals in the urban-dominated region may habituate them to non-lethal human disturbance [102,103], or they may reduce antipredator behavior with increasing exposure to high-risk situations (risk-allocation hypothesis, [104]). The majority of human encounters in the natural portions of our study area are with recreational hikers or cyclists, and thus nonlethal, while lethal encounters with poachers or domestic dogs are far rarer.

\section{Conclusions}

In general, an understanding of the adaptability of urban wildlife outside of North America, Europe, and Australia is lacking, and has even been hypothesized to be linked with a lack of urban-adapting carnivores [105]. Here, we describe the presence and ecology of a carnivore adjacent to areas with extremely high human densities in urbanizing Cape Town, demonstrating that carnivores can adapt to life on the edge of urban-dominated landscapes in the global South.

The mechanisms that facilitate carnivore population persistence and coexistence in anthropogenically disturbed landscapes include spatial avoidance of humans [106], or temporal avoidance of human activity where they spatially overlap [27]. We have demonstrated that caracals in the wildland-dominated region appear to spatially avoid humans. We found some evidence that caracals in the urban-dominated region avoid humans as well, but at finer scales and with a greater overall tolerance for human disturbance than the wildland-dominated subpopulation. Yet the urban matrix is inhospitable for adultsthe reproductive demographic of the population. The urban matrix presents a near absolute barrier to movement (Fig. 1b), and thus, the caracal subpopulations are extensively isolated, and effectively a closed and fragmented population. The Cape Peninsula is a dynamic system not only because of frequent fires, but also advancing anthropogenic development. Consequently, the long-term persistence of this population will be threatened by ongoing habitat transformation, and it is essential that this development be mitigated where feasible, including through the establishment of movement corridors. Further, the restoration of pine plantations (that were marginally avoided) could increase the amount of viable habitat for caracals and other wildlife. Charismatic carnivores are widely reported to have profound influence on ecosystem dynamics, provide socioeconomic benefits to society, and earn disproportionate attention in the media [34]. Local land managers and the general public have expressed interest in the conservation of this species, and thus management action is needed to prevent the defaunation of Table Mountain's wildlife extending to caracals. Achieving this goal, and conserving fauna globally throughout 
the rapidly expanding urban-wildland interface, requires new conservation strategies and initiatives that better accommodate the nuances for wildlife of living in human-dominated landscapes.

\section{Declarations}

\section{Ethics approval}

Animal handling, collaring, and sample collection was approved by the University of Cape Town Animal Ethics Committee (2014/V20/LS), Cape Nature (AAA007-0147-0056), and South Africa National Parks (2014/CRC/2014-017, 2015/CRC/2014-017, 2016/CRC/2014-017, 2017/CRC/2014-017).

\section{Consent for publication}

Not applicable.

\section{Availability of data}

The datasets generated and analyzed during the current study will be made available in the Dryad data repository.

\section{Competing interests}

The authors declare that they have no competing interests.

\section{Funding}

We thank the Claude Leon Foundation, Cape Leopard Trust, the University of Cape Town, Botanica Wines, Stellenbosch University, the National Research Foundation, the Institute for Communities and Wildlife in Africa (iCWild), Wildlife ACT, City of Cape Town, Experiment, and numerous private donors for funding fieldwork. We thank iCWild and University of California, Santa Cruz (UCSC) for support during manuscript preparation. We thank the City of Cape Town, Cape Leopard Trust, and UCSC for additional field equipment.

\section{Authors' contributions}

LEKS, JMB, and MJO conceptualized the study. LEKS collected, analyzed, and interpreted data, and wrote the manuscript. MSR analyzed data and contributed writing the manuscript. JAS, JPS, MSR, and CCW interpreted data. All authors read, edited, and approved the final manuscript.

\section{Acknowledgments}

We are grateful for the logistical and permitting support of SANParks and the City of Cape Town. We thank D.Winterton, L.Mossop, J.Broadfield, and numerous volunteer interns for their field assistance. We appreciate logistical support from the Society for Prevention of Cruelty to Animals (SPCA). Essential veterinary assistance was provided by B.Stevens, A.Knight, E.Jordan, T.Hepburn. 


\section{References}

1. Venter O, Sanderson E, Magrach A, Allan J, Beher J, Jones K, et al.: Sixteen years of change in the global terrestrial human footprint and implications for biodiversity conservation. Nat Commun 2016,7:12558.

2. Kareiva P, Watts S, McDonald R, Boucher T: Domesticated nature: Shaping landscapes and ecosystems for human welfare. Science 2007,316:1866-9.

3. Alberti M, Correa C, Marzluff JM, Hendry AP, Palkovacs EP, Gotanda KM, et al.: Global urban signatures of phenotypic change in animal and plant populations. PNAS 2017,114:8951-6.

4. Rebele F: Urban ecology and special features of urban ecosystems. Glob Ecol Biogeogr 1994,4:17387.

5. Tucker M, Böhning-Gaese K, Fryxell J, Moorter BV, Alberts S, et al.: Moving in the Anthropocene: Global reductions in terrestrial mammalian movements. Science 2018,359:466-9.

6. Suraci J, Frank L, Oriol-Cotterill A, Ekwanga S, Williams TM, Wilmers CC: Behavior-specific habitat selection by African lions may promote their persistence in a human-dominated landscape. Ecology 2019,100:e02644.

7. Frid A, Dill LM. Human-caused disturbance stimuli as a form of predation risk. Conserv Ecol 2002,6:11.

8. Collins C, Kays R: Causes of mortality in North American populations of large and medium-sized mammals. Anim Conserv 2011,14:474-83.

9. Flesch A: Influence of local and landscape factors on distributional dynamics: a species-centred, fitness-based approach. Proc R Soc B 2017,284:20171001.

10. Johnson HE, Lewis DL, Breck SW: Individual and population fitness consequences associated with large carnivore use of residential development. Ecosphere 2020,11:e03098.

11. Ceballos G, Ehrlich PR, Barnosky AD, García A, Pringle RM, Palmer TM: Accelerated modern humaninduced species losses: Entering the sixth mass extinction. Sci Adv 2015,1:e1400253.

12. Dirzo R, Young H, Galetti M, Ceballos G, Isaac N, Collen B: Defaunation in the Anthropocene. Science 2014,345:401-6.

13. Matthews B, Narwani A, Hausch S, Nonaka E, Peter H, Yamamichi M, et al.: Toward an integration of evolutionary biology and ecosystem science. Ecol Lett 2011,14:690-701.

14. Tuomainen U, Candolin U: Behavioural responses to human-induced environmental change. Biol Rev 2011,86:640-57.

15. Wong BBM, Candolin U: Behavioral responses to changing environments. Behav Ecol 2015,26:66573.

16. Ciuti S, Northrup JM, Muhly TB, Simi S, Musiani M, Pitt JA, et al.: Effects of humans on behaviour of wildlife exceed those of natural predators in a landscape of fear. PLOS One 2012,7:e50611. 
17. Clinchy M, Zanette LY, Roberts D, Suraci JP, Buesching CD, Newman C, et al.: Fear of the human "super predator" far exceeds the fear of large carnivores in a model mesocarnivore. Behav Ecol 2016,27:1826-32.

18. Suraci JP, Clinchy M, Zanette LY, Wilmers CC: Fear of humans as apex predators has landscape-scale impacts from mountain lions to mice. Ecol Lett 2019,22:1578-86.

19. Nickel B, Suraci J, Allen M, Wilmers C: Human presence and human footprint have non-equivalent effects on wildlife spatiotemporal habitat use. Biol Conserv 2020,241:108383.

20. Wilmers C, Wang Y, Nickel B, Houghtaling, P, Shakeri Y, Allen M, et al.: Scale dependent behavioral responses to human development by a large predator, the puma. PLOS ONE 2013,8:e60590.

21. Wilson RR, Gilbert-Norton L, Gese EM: Beyond use versus availability: behaviour-explicit resource selection. Wildlife Biol 2012,18:424-30.

22. Moorter $\mathrm{B}$, Rolandsen $\mathrm{CM}$, Basille M, Gaillard $\mathrm{J}$ : Movement is the glue connecting home ranges and habitat selection. J Anim Ecol 2015,85:21-31.

23. Matthiopoulos J, Hebblewhite M, Aarts G, Fieberg J: Generalized functional responses for species distributions. Ecology 2011,92:583-9.

24. Duparc A, Garel M, Marchand P, Dubray D, Maillard D, Loison A: Revisiting the functional response in habitat selection for large herbivores: a matter of spatial variation in resource distribution? Behav Ecol 2019,30:1725-33.

25. Mason TH, Fortin D: Functional responses in animal movement explain spatial heterogeneity in animal-habitat relationships. J Anim Ecol 2017,86:960-71.

26. Wittemeyer G, Northrup J, Bastille-Rousseau G: Behavioural valuation of landscapes using movement data. Philos Trans R Soc B 2019,374:20180046.

27. Gaynor KM, Hojnowski ChE, Carter NH, Brashares JS: The influence of human disturbance on wildlife nocturnality. Science 2018,360:1232-5.

28. Grilo C, Lucas PM, Fernández-Gil A, Seara M, Costa G, Roque S, et al.: Refuge as major habitat driver for wolf presence in human-modified landscapes. Anim Conserv 2019,22:59-71.

29. Muhly TB, Semeniuk C, Massolo A, Hickman L, Musiani M: Human activity helps prey win the predator-prey space race. PLOS ONE 2011,6:e17050.

30. Rogala J, Hebblewhite M, Whittington J, Musiani M, White C, Coleshill J: Human activity differentially redistributes large mammals in the Canadian Rockies National Parks. Ecol Soc 2011,16:16.

31. Schuette P, Creel S, Christianson D: Coexistence of African lions, livestock, and people in a landscape with variable human land use and seasonal movements. Biol Conserv 2013,157:148-54.

32. Suraci J, Nickel B, Wilmers C: Fine-scale movement decisions by a large carnivore inform conservation planning in human-dominated landscapes. Landsc Ecol 2020,35:1635-49.

33. Crooks. Relative sensitivities of mammalian carnivores to habitat fragmentation. Conserv Biol 2002,16:488-502. 
34. Ripple WJ, Estes JA, Beschta RL, Wilmers CC, Ritchie EG, Hebblewhite M, et al. : Status and ecological effects of the world's largest carnivores. Science 2014,343:1241484.

35. Wolf C, Ripple WJ. Prey depletion as a threat to the world's large carnivores. Roy Soc Open Sci 2016,3:160252.

36. Drouilly M, O'Riain MJ: Wildlife winners and losers of extensive small-livestock farming: a case study in the South African Karoo. Biodivers Conserv 2019,28:1493-511.

37. Bateman PW, Fleming PA: Big city life: carnivores in urban environments. J Zool 2012,287:1-23.

38. Ritchie EG, Johnson CN: Predator interactions, mesopredator release and biodiversity conservation. Ecol Lett 2009,12:982-98.

39. Schuette $P$, Wagner AP, Wagner ME, Creel S: Occupancy patterns and niche partitioning within a diverse carnivore community exposed to anthropogenic pressures. Biol Conserv 2013,158:301-12.

40. Fuller T, DeStefano S, Warren P. Carnivore behavior and ecology, and relationship to urbanization. In: Gehrt S, Riley S, Cypher B, editors. Urban carnivores: ecology, conflict, and conservation. Baltimore, Maryland, USA 312pp: The John Hopkins University Press, 2010. p. 13-9.

41. Litvaitis JA, Villafuerte R: Intraguild predation, mesopredator release, and prey stability. Conserv Biol 1996,10:676-7.

42. Gehrt SD, Prange S: Interference competition between coyotes and raccoons: a test of the mesopredator release hypothesis. Behav Ecol 2006,18:204-14.

43. Drouilly M, Tafani M, Nattrass N, O'Riain J: Spatial, temporal and attitudinal dimensions of conflict between predators and small-livestock farmers in the Central Karoo. Afr J Range For Sci 2018,35:245-55.

44. Leighton GRM, Bishop JM, O'Riain MJ, Broadfield J, Meröndun J, Avery G, et al.: An integrated dietary assessment increases feeding event detection in an urban carnivore. Urban Ecosyst. 2020,23:569-83.

45. Serieys LE, Bishop J, Okes N, Broadfield J, Winterton DJ, Poppenga RH, et al.: Widespread anticoagulant poison exposure in predators in a rapidly growing South African city. Sci Total Environ 2019,666:581-90.

46. Schnetler AK, Radloff FGT, O'Riain MJ: Medium and large mammal conservation in the City of Cape Town: factors influencing species richness in urban nature reserves. Urban Ecosyst 2020,1-18.

47. Nattrass N, O'Riain MJ: Contested natures: conflict over caracals and cats in Cape Town, South Africa. J Urban Ecol 2020,6:juaa019.

48. Viljoen S, O'Riain MJ, Penzhorn BL, Drouilly M, Serieys LEK, Cristescu B, et al.: Molecular detection of tick-borne pathogens in caracals (Caracal caracal) living in human-modified landscapes of South Africa. Parasite Vector 2020,13:220.

49. Rebelo A, Boucher C, Helme N, Mucina L, Rutherford M: Fynbos biome. Strelitzia 2006,19:53-219.

50. Schroeder MA, Robb LA, Braun C: Criteria for gender and age. The Wildlife Society Bethesda. 2005

51. Riley S, Brown J, Sikich JA, Schoonmaker CM, Boydston EE, McCleery RA, et al.: Wildlife friendly roads: the impacts of roads on wildlife in urban areas and potential remedies. In: Urban Willdlife 
Conservation. New York, New York: Springer, 2014. p. 323-60.

52. Gelmen A, Hill J: Data Analysis Using Regression and Multilevel/Heirarchical Models. Cambridge University Press. 2007

53. Zuur A, Leno E, Elphick C: A protocol for data exploration to avoid common statistical problems. Methods Ecol Evol 2010,1:3-14.

54. Thurfjell H, Ciuti S, Boyce M: Applications of step-selection functions in ecology and conservation. Mov Ecol 2014,2:4.

55. Duchesne T, Fortin D, Courbin N: Mixed conditional logistic regression for habitat selection studies. $J$ Anim Ecol 2010,79:548-55.

56. Fortin D, Beyer H, Boyce M, Smith D, Duchesne T, Mao J: Wolves influence elk movements: behavior shapes a trophic cascade in Yellowstone National Park. Ecology 2005,86:1320-30.

57. Forester JD, Im H, Rathouz PJ. Accounting for animal movement in estimation of resource selection functions: sampling and data analysis. Ecology 2009,90:3554-65.

58. Nicosia A, Duchesne T, Rivest L, Fortin D. A multi-state conditional logistic regression model for the analysis of animal movement. Ann App/ Stat 2016,11:1537-60.

59. Craiu R, Duchesne T, Fortin D: Inference methods for the conditional logistic regression model with longitudinal data. Biometrical J 2008,50:97-109.

60. Koper N, Manseau M: Generalized estimating equations and generalized linear mixed effects models for modelling resource selection. J Appl Ecol 2009,46:590-99.

61. Prima MC, Duchesne T, Fortin D: Robust inference from conditional logistic regression applied to movement and habitat selection analysis. PLOSONE 2017,12:e0169779.

62. Therneau TM. survival: Survival Analysis. 2018

63. R Core Team: R: A Language and Environment for Statistical Computing. R Foundation for Statistical Computing. 2019

64. Kohl MT, Stahler DR, Metz MC, Forester JD, Kauffman MJ, Varley N, et al.: Diel predator activity drives a dynamic landscape of fear. Ecol Monogr 2018,88:638-52.

65. Manly B, McDonald L, Thomas D, McDonald T, Erickson W. Resource selection by animals. Netherlands: Springer, 2002.

66. Fortin D, Fortin M-E, Beyer HL, Duchesne T, Courant S, Dancose K: Group-size-mediated habitat selection and group fusion-fission dynamics of bison under predation risk. Ecology 2009,90:248090.

67. Hertel AG, Swenson JE, Bischof R: A case for considering individual variation in diel activity patterns. Behav Ecol 2017,28:1524-31.

68. Ordiz A, Støen O-G, Delibes M, Swenson JE: Predators or prey? Spatio-temporal discrimination of human-derived risk by brown bears. Oecologia 2011,166:59-67.

69. Chetkiewicz CB, St. Clair CC, Boyce MS: Corridors for conservation: integrating pattern and process. Annu Rev Ecol Evol Syst 2006,37:317-42. 
70. Hawlena D, Saltz D, Abramsky Z, Bouskila A: Ecological trap for desert lizards caused by anthropogenic changes in habitat structure that favor predator Aactivity. Conserv Bio/2010,24:8039.

71. Wittemyer G, Northrup JM, Bastille-Rousseau G: Behavioural valuation of landscapes using movement data. Phil Trans R Soc B 2019,374:20180046.

72. Knopff A, Knopff KH, Boyce MS, Clair C: Flexible habitat selection by cougars in response to anthropogenic development. Biol Conserv 2014,178:136-45.

73. Weisbein $\mathrm{Y}$, Mendelssohn $\mathrm{H}$ : The biology and ecology of the caracal Felis caracal in the northern Aravah valley of Israel. Cat News1990,12:20-2.

74. Hopcraft J, Sinclair A, Packer C: Planning for success: Serengeti lions seek prey accessibility rather than abundance. J Anim Ecol 2005,74:559-66.

75. Smith J, Donadio E, Pauli J, Sheriff M, Bidder O, Middleton A: Habitat complexity mediates the predator-prey space race. Ecology 2019,0:e02724.

76. Pausas J, Keeley J: A burning story: The role of fire in the history of life. Bioscience 2009,59:593601.

77. Haslem A, Kelly LT, Nimmo DG, Watson SJ, Kenny SA, Taylor RS, et al.: Habitat or fuel? Implications of long-term, post-fire dynamics for the development of key resources for fauna and fire. $J$ Appl Ecol 2011,48:247-56.

78. Eby SL, Anderson TM, Mayemba EP, Ritchie ME: The effect of fire on habitat selection of mammalian herbivores: the role of body size and vegetation characteristics. J Anim Ecol 2014,83:1196-205.

79. Lino S, Sillero N, Torres J, Santos X, Álvares F: The role of fire on wolf distribution and breeding-site selection: Insights from a generalist carnivore occurring in a fire-prone landscape. Landscape Urban Plan 2019,183:111-21.

80. Cunningham S, Kirkendall L, Warren B: Gray fox and coyote abundance and diet responses after a wildfire in central Arizona. West N Am Nat 2006,66:169-80.

81. Jennings MK, Lewison RL, Vickers TW, Boyce WM: Puma response to the effects of fire and urbanization. J Wildl Manag 2016,80:221-34.

82. Sensenig RL, Demment MW, Laca EA: Allometric scaling predicts preferences for burned patches in a guild of East African grazers. Ecology 2010,91:2898-907.

83. Monasmith TJ, Demarais S, Root JJ, Britton CM: Short-term fire effects on small mammal populations and vegetation of the northern Chihuahuan desert. Int J Eco/2010,2010:1-9.

84. Fisher J, Wilkinson L: The response of mammals to forest fire and timber harvest in the North American boreal forest. Mammal Rev 2005,35:51-81.

85. Campbell B: Plant spinescence and herbivory in a nutrient poor ecosystem. Oikos 1986,47:168-72.

86. Bond W, Breytenbach G: Ants, rodents and seed predation in Proteaceae. S Afr J Zool 1985,20:150-4.

87. Hensbergen $\mathrm{H}$ van, Botha $\mathrm{S}$, Forsyth $\mathrm{G}$, Maitre $\mathrm{DL}$ : Do small mammals govern vegetation recovery after fire in fynbos? In: Wilgen B van, Richardson D, Kruger F, Hensbergen $\mathrm{H}$ van, editors. Fire in South 
African mountain fynbos: Ecosystem, community, and species response at Swatboskloof. Berlin: Springer-Verlag, 1992. p. 182-202.

88. Bowler DE, Benton TG: Causes and consequences of animal dispersal strategies: relating individual behaviour to spatial dynamics. Biol Rev 2005,80:205-25.

89. Elliot NB, Cushman SA, Loveridge AJ, Mtare G, Macdonald DW: Movements vary according to dispersal stage, group size, and rainfall: the case of the African lion. Ecology 2014,95:2860-9.

90. O'Neill HMK, Durant SM, Woodroffe R: What wild dogs want: habitat selection differs across life stages and orders of selection in a wideranging carnivore. BMC Zoology 2020,5:1.

91. Hinton JW, Proctor C, Kelly MJ, Manen FT van, Vaughan MR, Chamberlain MJ: Space use and habitat selection by resident and transient red wolves (Canis rufus). PLOS ONE 2016,11:e0167603.

92. Riley SP, Sauvajot RM, Fuller TK, York EC, Kamradt DA, Bromley C, et al.: Effects of urbanization and habitat fragmentation on bobcats and coyotes in Southern California. Conserv Bio/ 2003,17:566-76.

93. Palomares F, Delibes M, Ferreras P, Fedriani J, Calzada J, Revilla E: Iberian lynx in a fragmented landscape: predispersal, dispersal, and postdisperal habitats. Conserv Bio/ 2000,14:809-18.

94. Lowry H, Lill A, Wong BB: Behavioural responses of wildlife to urban environments. Biol Rev 2013,88:537-49.

95. Evans MJ, Rego JEHW, Rittenhouse TA: Hourly movement decisions indicate how a large carnivore inhabits developed landscapes. Oecologia 2019,190:11-23.

96. Athreya V, Odden M, Linnell JD, Krishnaswamy J, Karanth U: Big cats in our backyards: Persistence of large carnivores in a human dominated landscape in India. PLOS ONE 2013,8:e57872.

97. Smith JA, Donadio E, Bidder OR, Pauli JN, Sheriff MJ, Perrig PL, et al.: Where and when to hunt? Decomposing predation success of an ambush carnivore. Ecology 2020,e03172.

98. Smith JA, Suraci JP, Clinchy M, Crawford A, Roberts D, Zanette LY, et al.: Fear of the human 'super predator' reduces feeding time in large carnivores. Proc Royal Soc B 2017,284:20170433.

99. Valeix M, Hemson G, Loveridge A, Mills G, Macdonald D: Behavioural adjustments of a large carnivore to access secondary prey in a human-dominated landscape. J Appl Ecol 2012,49:73-81.

100. Tigas L, Vuren VV, Sauvajot R: Behavioral responses of bobcats and coyotes to habitat fragmentation and corridors in an urban environment. Biol Conserv 2002,108:299-306.

101. Dupke C, Bonenfant C, Reineking B, Hable R, Zeppenfeld T, Ewald M, et al.: Habitat selection by a large herbivore at multiple spatial and temporal scales is primarily governed by food resources. Ecography 2016,40:1014-27.

102. Rodriguez-Prieto I, Fernández-Juricic E, Martín J, Regis Y: Antipredator behavior in blackbirds: habituation complements risk allocation. Behav Ecol 2009,20:371-7.

103. Schell CJ, Young JK, Lonsdorf EV, Santymire RM, Mateo JM: Parental habituation to human disturbance over time reduces fear of humans in coyote offspring. Ecol Evol 2018,8:12965-80.

104. Lima SL, Bednekoff PA: Temporal variation in danger drives antipredator behavior: The predation risk allocation hypothesis. Am Nat 1999,153:649-59. 
105. lossa G, Soulsbury C, Baker P, Harris S: A taxonomic analysis of urban carnivore ecology. In: Gehrt S, Riley S, Cypher B, editors. Urban Carnivores: Ecology, conflict, and conservation. Baltimore, Maryland, USA 312pp: The John Hopkins University Press, 2010. p.173-84

106. Lamb CT, Ford AT, McLellan BN, Proctor MF, Mowat G, Ciarniello L, et al.: The ecology of humancarnivore coexistence. PNAS 2020,117:17876-83.

\section{Tables}

Table 1. Optimal knot values and the results of $\mathrm{K}$-fold cross validation values across all modeled datasets and diel periods. Knot breakpoints (represented as the distance from the urban-natural boundary) were determined using segmented regressions for adults and subadults in the urban-dominated region that indicated the functional shift in avoidance-selection trends from the urban interface to natural areas. 


\begin{tabular}{|c|c|c|c|c|c|}
\hline \multirow[b]{2}{*}{ Demographic } & \multirow[b]{2}{*}{ Diel period } & \multirow[b]{2}{*}{$\begin{array}{l}\text { Movement } \\
\text { dataset }\end{array}$} & \multirow[b]{2}{*}{$\begin{array}{l}\text { Knot } \\
\text { distance } \\
\text { (m) }\end{array}$} & \multicolumn{2}{|c|}{ K-Fold Validation $r_{s}$} \\
\hline & & & & $\begin{array}{l}\text { Observed } \\
\text { mean (SD) }\end{array}$ & $\begin{array}{l}\text { Random } \\
\text { mean (SD) }\end{array}$ \\
\hline \multirow[t]{6}{*}{$\begin{array}{l}\text { Urban-dominated region } \\
\text { adults }\end{array}$} & Composite & 3-hour & 63 & $0.97(0.01)$ & $\begin{array}{l}-0.004 \\
(0.23)\end{array}$ \\
\hline & Day & 3-hour & 57 & $0.95(0.02)$ & $-0.01(0.23)$ \\
\hline & Night & 3-hour & 74 & $0.93(0.03)$ & $-0.04(0.22)$ \\
\hline & Composite & 20-min & 56 & $0.88(0.04)$ & $0.02(0.24)$ \\
\hline & Day & 20-min & 44 & $0.88(0.05)$ & $-0.03(0.21)$ \\
\hline & Night & 20-min & 115 & $0.77(0.07)$ & $0.02(0.24)$ \\
\hline \multirow{6}{*}{$\begin{array}{l}\text { Urban-dominated region } \\
\text { subadult males }\end{array}$} & Composite & 3-hour & 142 & $0.91(0.03)$ & $0.01(0.22)$ \\
\hline & Day & 3-hour & 153 & $0.88(0.04)$ & $-0.01(0.24)$ \\
\hline & Night & 3-hour & 126 & $0.81(0.07)$ & $-0.02(0.22)$ \\
\hline & Composite & 20-min & 91 & $0.71(0.10)$ & $\begin{array}{l}-0.004 \\
(0.21)\end{array}$ \\
\hline & Day & 20-min & 89 & $0.53(0.16)$ & $0.01(0.26)$ \\
\hline & Night & 20-min & 99 & $0.60(0.13)$ & $0.02(0.24)$ \\
\hline \multirow{6}{*}{$\begin{array}{l}\text { Wildland-dominated region } \\
\text { adults }\end{array}$} & Composite & 3-hour & NA & $0.62(0.08)$ & $-0.03(0.25)$ \\
\hline & Day & 3-hour & NA & $0.65(0.08)$ & $0.003(0.22)$ \\
\hline & Night & 3-hour & NA & $0.47(0.11)$ & $-0.03(0.23)$ \\
\hline & Composite & $20-\min$ & NA & $0.63(0.10)$ & $-0.02(0.24)$ \\
\hline & Day & 20-min & NA & $0.42(0.12)$ & $0.03(0.24)$ \\
\hline & Night & 20-min & NA & $0.74(0.08)$ & $0.02(0.22)$ \\
\hline
\end{tabular}

Figures 


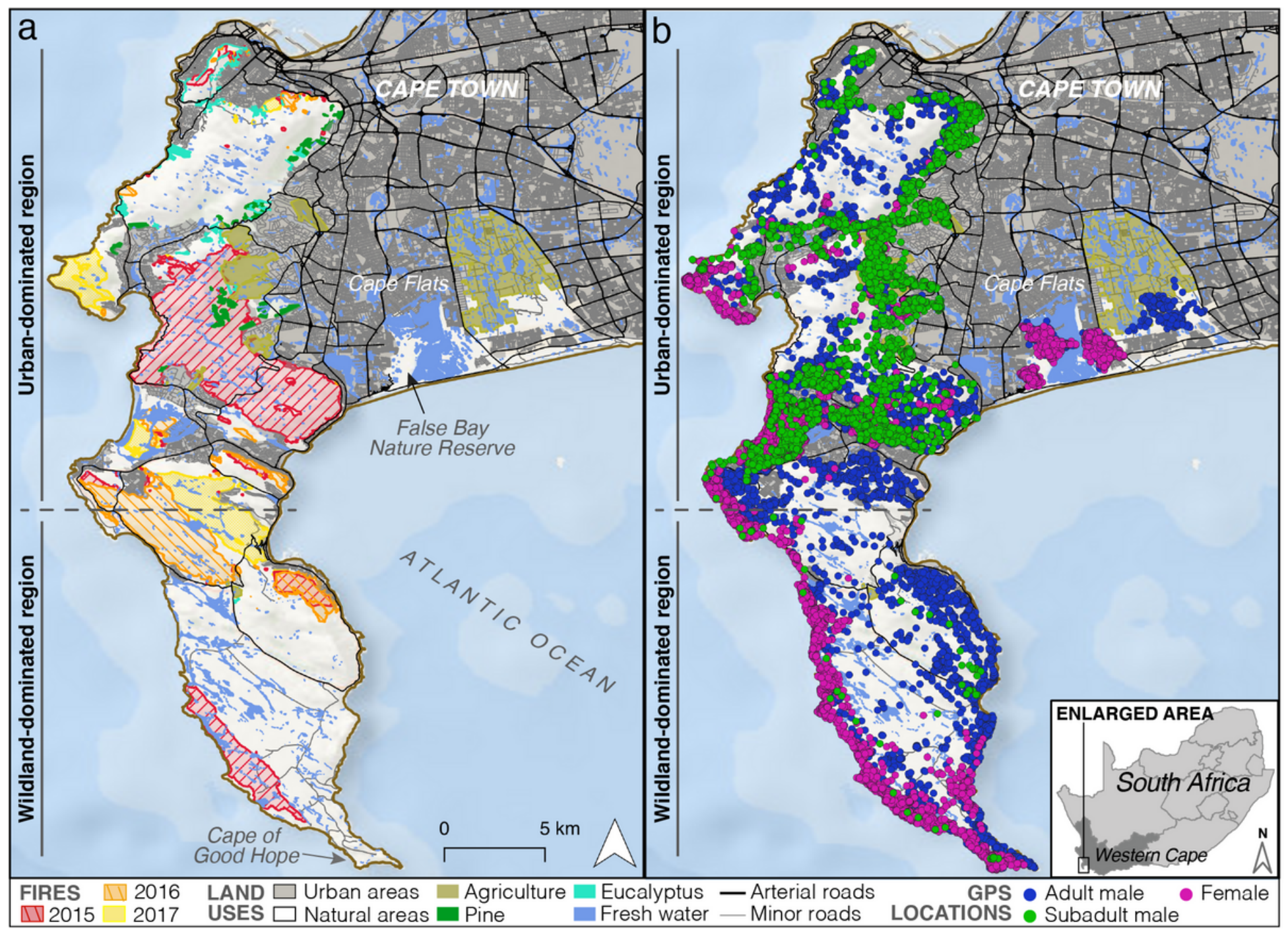

Figure 1

Map of the study area in Cape Town, South Africa showing the two subregions (urban-dominated and wildland-dominated). a) Map of key land uses and extent of burned areas. b) Three-hour GPS collar locations for adult females, adult males, and subadult males. Note: The designations employed and the presentation of the material on this map do not imply the expression of any opinion whatsoever on the part of Research Square concerning the legal status of any country, territory, city or area or of its authorities, or concerning the delimitation of its frontiers or boundaries. This map has been provided by the authors. 

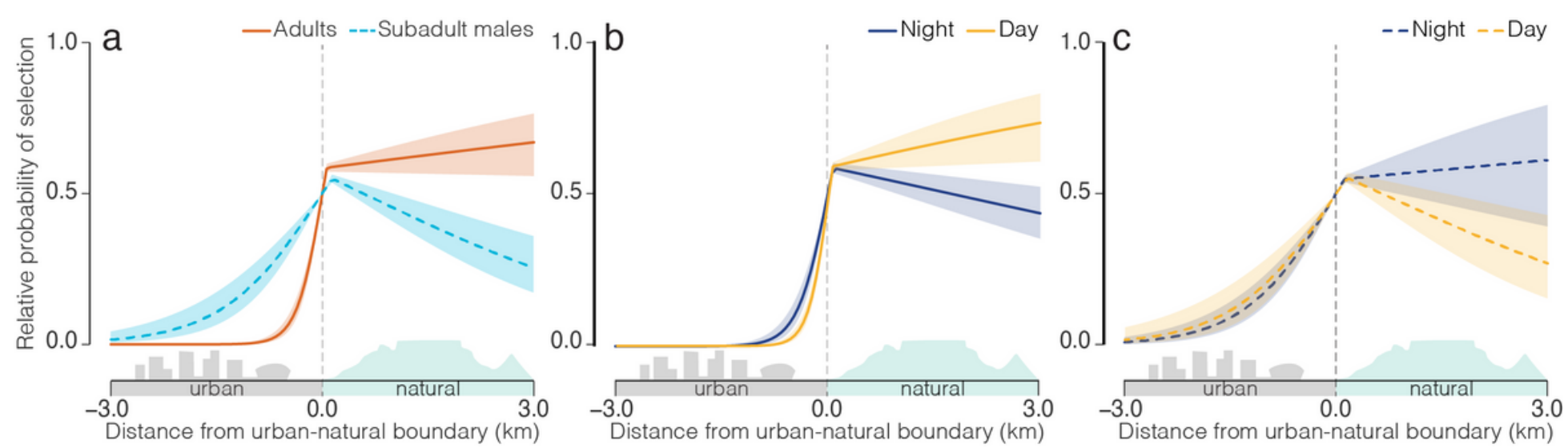

Figure 2

Relative probability of selection for distance from the urban-natural boundary for caracals in the urbandominated region based on 3-hour datasets. a) Selection profile based on the composite dataset for adults and subadult males. b) Selection profile partitioned by diel period for adult males and females. c) Selection profile partitioned by diel period for subadult males.

COVARIATE KEY: OEverywhere $\mathbf{q}$ Urban interface $\boldsymbol{\nabla}$ Natural areas

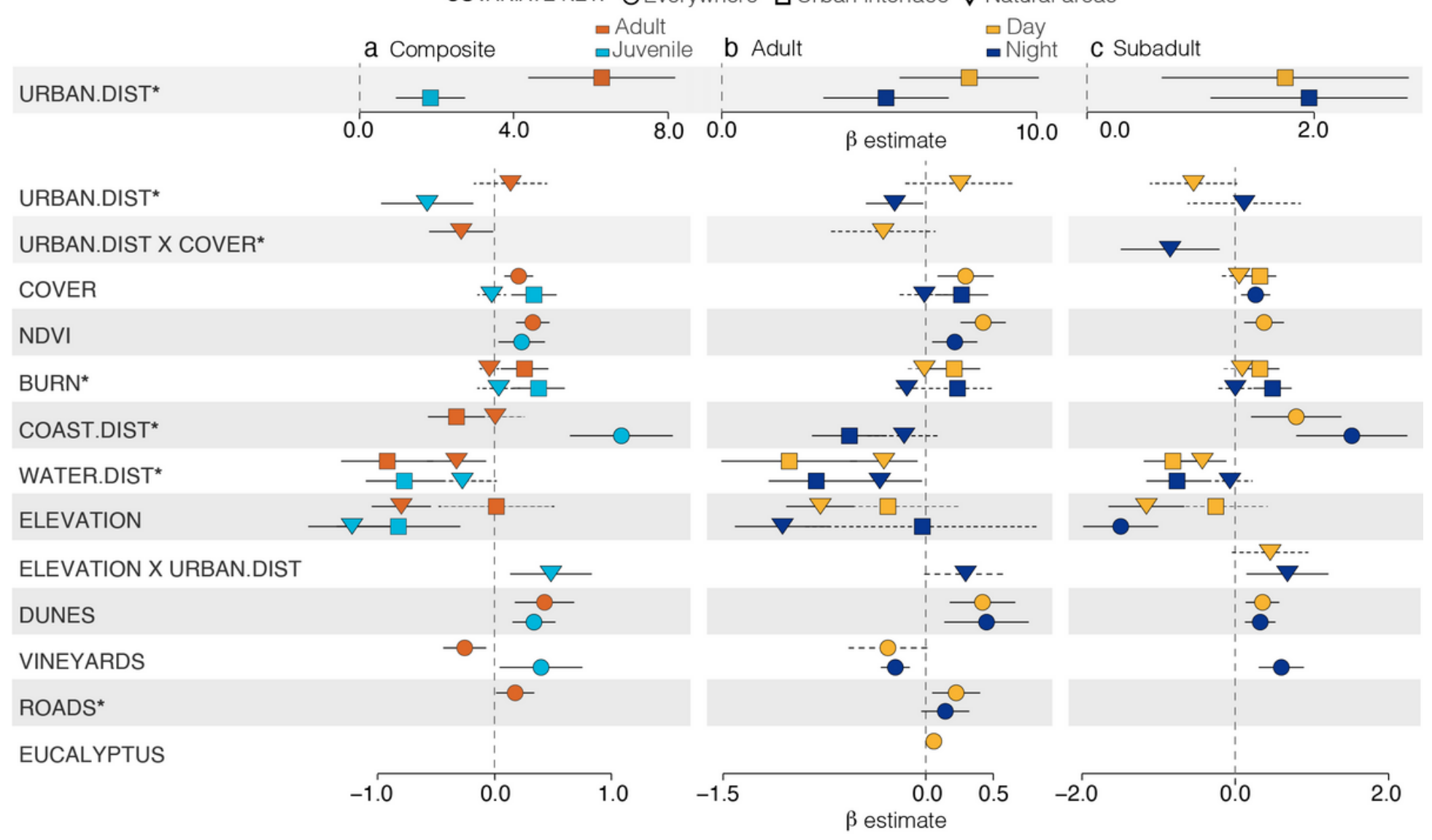

\section{Figure 3}

Selection estimates and 95\% confidence intervals for the (a) composite, (b) day and night 3-hr dataset top models for adults, and (c) subadult males in the urban-dominated region. Segmented models were used for caracals sampled in the urban-dominated region, resulting in cases where covariates were split, 
resulting in cases where $B$ coefficients were generated for when individuals were situated within the urban interface (squares) or natural areas (triangles). When covariates were not split, the $ß$ coefficients (circles) applied throughout the landscape irrespective of whether individuals were located within the urban interface or within natural areas. The distance from the urban-natural boundary (URBAN.DIST) covariate was always split, resulting in two ß coefficients with substantially different values, thus plotted on two separate axes. * indicates a covariate where positive $B$ values indicate a negative association, and negative $B$ values indicate a positive association. Where $95 \%$ confidence intervals are represented by a dashed line, the $ß$ estimate is not significant at $a \leq 0.05$.

\section{URBAN.DIST*}

URBAN.DIST^2

URBAN.DIST X COVER*

URBAN.DIST^2 X COVER

COVER

NDVI

COAST.DIST*

WATER.DIST*

ELEVATION

DUNES
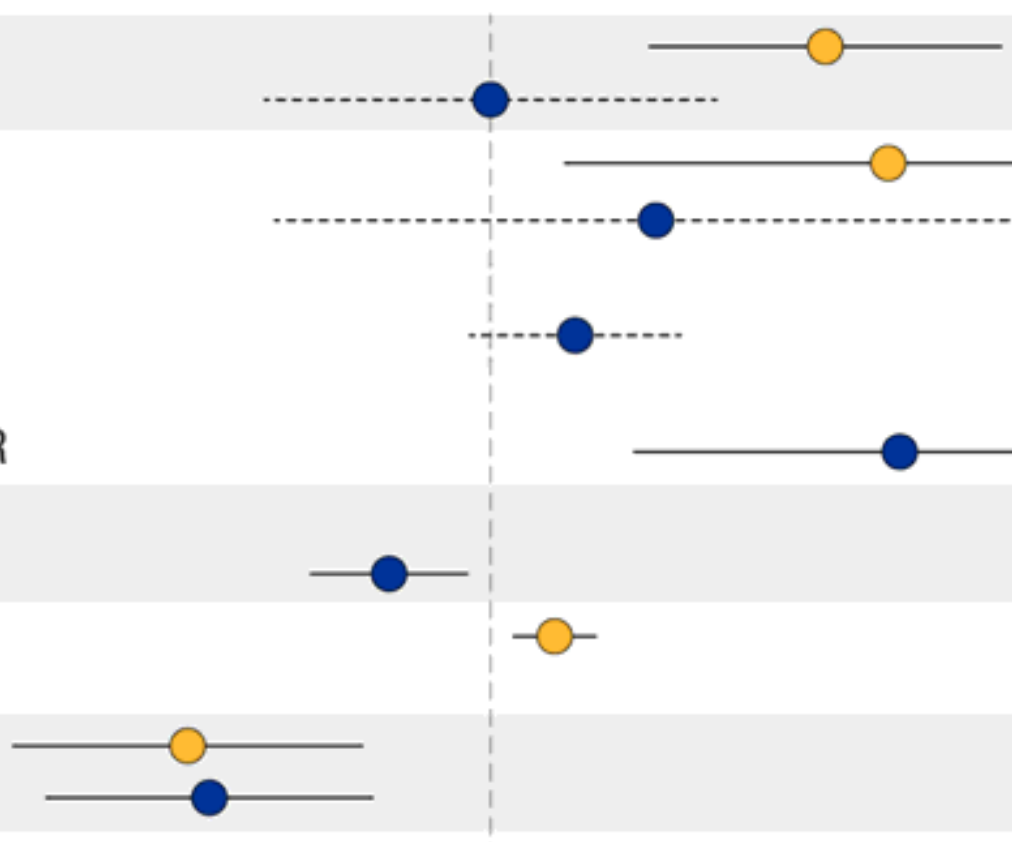

$\square$ Day

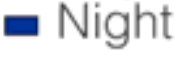




\section{_Urban adults - -Urban subadults —Wildland adults}

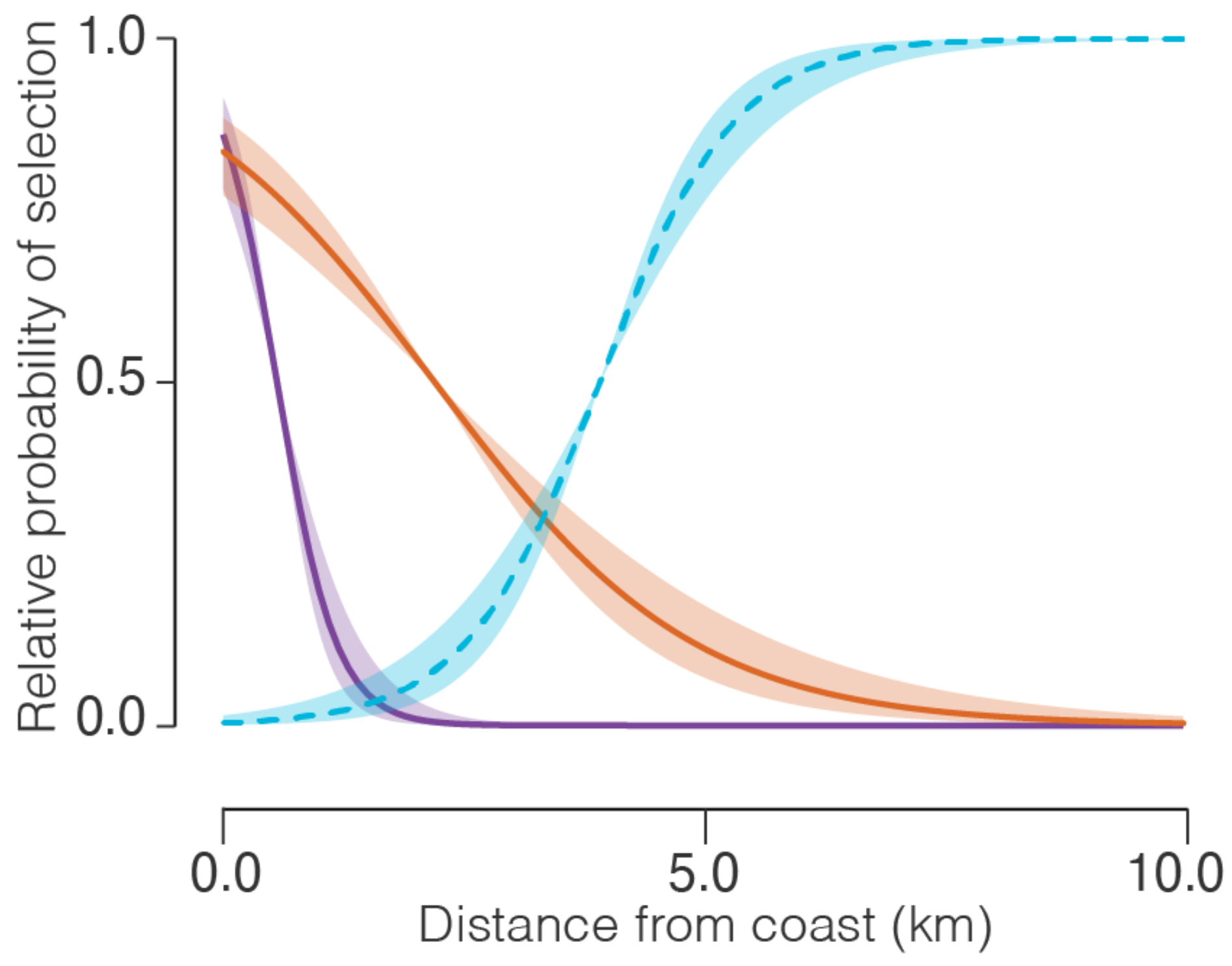

\section{Figure 5}

The relatively probability of selection for the coast for adults in the wildland and urban-dominated regions, and subadult males in the urban-dominated region. The selection trend illustrated for adults in the urban-dominated region represents selection for the coast only when individuals are situated within the urban interface, whereas for subadults, the illustrated selection trend is the same whether individuals are situated within the urban interface or natural areas. Figure based on night 3-hr dataset for each subgroup. 


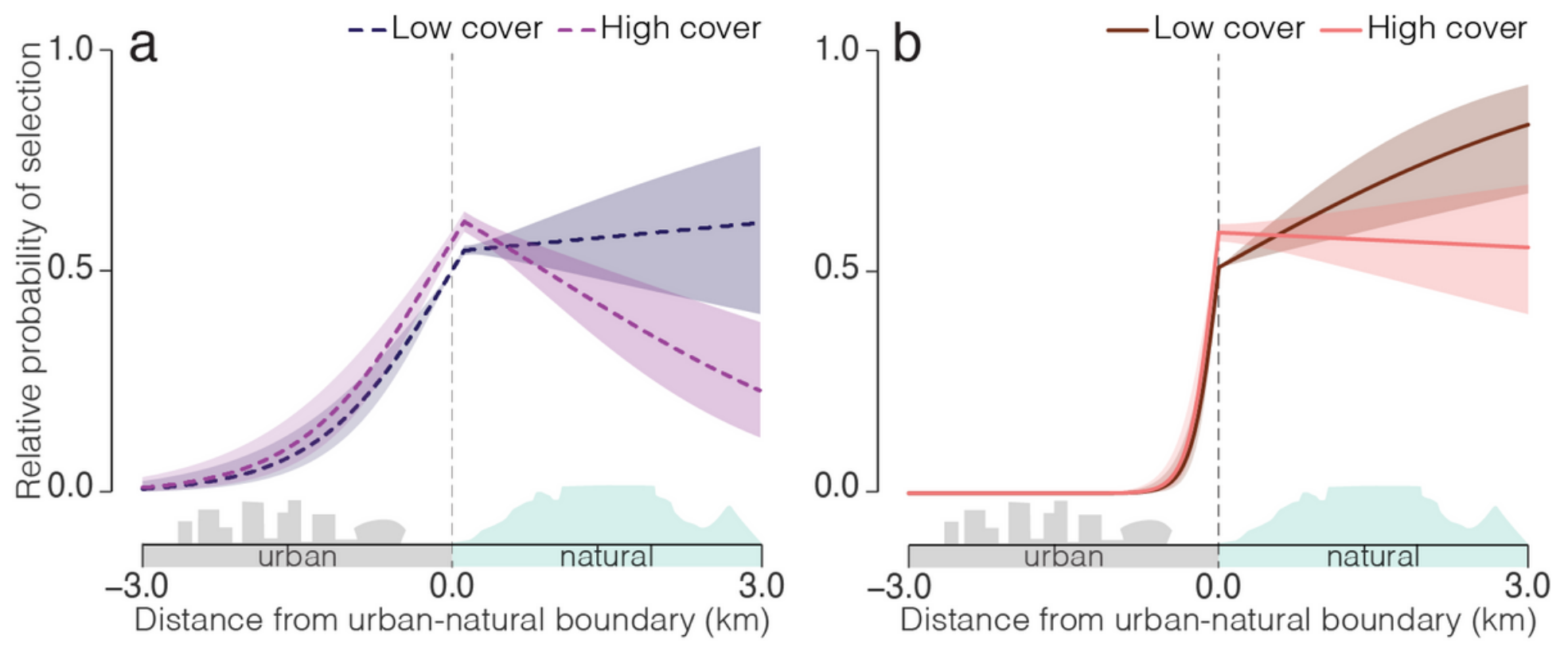

\section{Figure 6}

Interaction between the distance from the urban-natural boundary and available vegetative cover. a) The interaction for subadults in the urban-dominated region at night shows strong selection for close proximity to the urban-natural boundary in the presence of high cover, but a neutral relationship in the absence of high cover. Figure based on results for the 3-hour dataset. b) During the day, adults in the urban-dominated region strongly avoid the urban-natural boundary in the absence of high cover but select for close proximity to the urban-natural boundary when high cover is available. Figure based on results for the 20-min dataset. 


\section{- Urban adult natural areas _Urban adult urban interface - -Urban subadult urban interface}
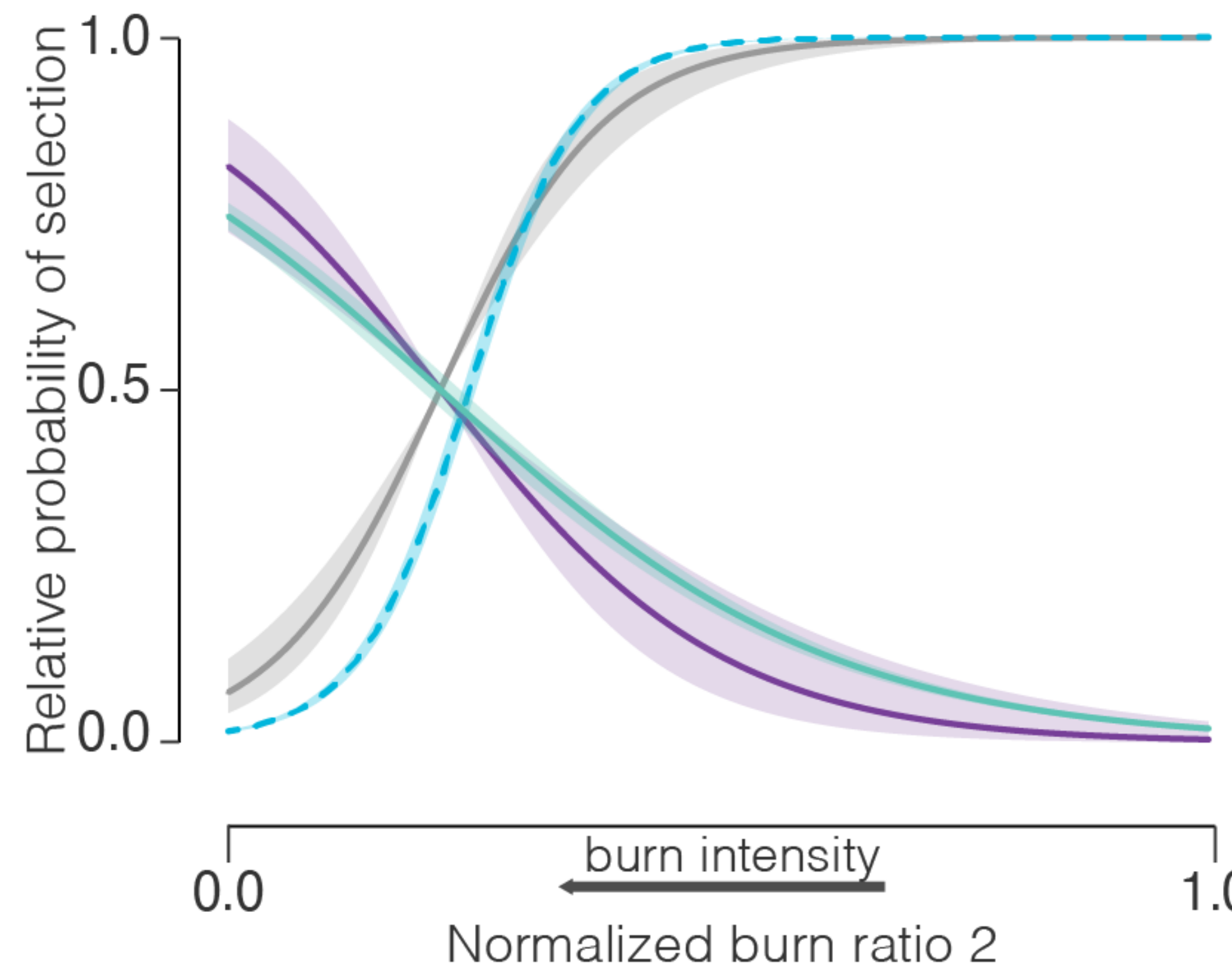

\section{Figure 7}

Avoidance and selection of burned areas (measured as the vegetation index normalized burn ratio 2 [NBR2]) depended on region, age class, and for adults and subadults in the urban-dominated region, where on the landscape individuals were situated (e.g., within urban interface or natural areas). Figure based on night 20-min dataset for each group. More severe fire damage is represented by lower NBR2 values, while greenness (and a lack of fire damage) increases with higher NBR2 values.

\section{Supplementary Files}

This is a list of supplementary files associated with this preprint. Click to download. 
- CCUrbanMoveSuppFigs.docx

- CCUrbanMoveSuppTables.docx

- CcMovementSuppMethods010421.docx 